\title{
Performance of Children and Adolescents on Random Number Generation as a Measure of Executive Functions
}

\author{
Georgios Chatzopoulos ${ }^{1}$, Magda Dinou ${ }^{1} \&$ Hariklia Proios ${ }^{1}$ \\ ${ }^{1}$ Educational and Social Policy, University of Macedonia, Thessaloniki, Greece \\ Correspondence: Georgios Chatzopoulos, Educational and Social Policy, University of Macedonia, Thessaloniki, \\ Egnatia 156, Greece. Tel: 30-2310-891-630.
}

\author{
Received: March 14, 2021 Accepted: April 14, 2021 Online Published: April 23, 2021 \\ doi:10.5539/jedp.v11n1p37 URL: http://doi.org/10.5539/jedp.v11n1p37
}

\begin{abstract}
This study investigated the age-related differences in the random number generation (RNG) of children aged 7 to 15 years old $(n=106)$ divided into three groups $(7-9,10-12$ and $13-15$ years of age) as it was compared to computer-generated pseudorandom sequences. The results showed that there was an age effect on four out of seven indices of randomization that are known to tap the Inhibition ability and the Updating ability (i.e., active manipulation of relevant information in working memory). The participants' (children's and adolescents'; $n=106$ ) responses were significantly different from pseudorandom sequences $(n=106)$ produced by the RgCalc program and no gender differences were observed. The RNG task indices that reflect inhibition ability did not correlate with the participants' performance on the Stroop color-word task. The development of executive functions in school-aged children and adolescents is discussed.
\end{abstract}

Keywords: executive functions, random number generation, children, working memory, inhibition

\section{Introduction}

\subsection{Theoretical Background}

Regarding education, executive functions (EF) are used daily especially in various cognitive functions, such as working memory, attention, cognitive flexibility, problem solving, inhibitory control, verbal fluency, and speed of processing (Chan, Shum, Toulopoulou, \& Chen, 2008; Faria, Alves, \& Charchat-Fichman, 2015; Meixner, Warner, Lensing, Schiefele, \& Elsner, 2019). EF mature throughout childhood into adolescence (Diamond, 2006, pp 83-88). A relatively easy to administer task is the Random Number Generation (RNG); RNG concerns the random production of numbers to examine EF. An RNG task employs inhibitory control (Inhibition) and the ability to update verbal production (i.e., Updating), while keeping in working memory previous answers; these abilities tap different sets of randomness indices (Miyake et al., 2000). Despite RNG's easy administration and usefulness (Brugger, 1997; Geisseler et al., 2016) a recent scoping review demonstrates that this task is not frequently used in order to investigate EF in adolescent populations (Nyongesa et al., 2019).

Executive functioning (EF) and academic performance show an interrelated trend (Cortés Pascual, Moyano Muñoz, \& Quilez Robres, 2019; Visu-Petra, Cheie, Benga, \& Miclea, 2011). Working memory at five years of age is a better predicter than intelligence quotient (IQ) for the effective acquisition of scholastic skills (Alloway \& Alloway, 2010). Likewise, children with low working memory span present difficulties in sustained attention, problem-solving, and self-monitoring (Alloway, Gathercole, Kirkwood, \& Elliott, 2009).

Historically, Reichenbach (1949) supported the idea that individuals are unable to demonstrate almost perfect randomization performance (Reichenbach, 1949, as cited in Wagenaar, 1972). Extensive previous research has been done using randomization tasks applied to normal adult populations as well as adults with psychiatric and neurological conditions (Baddeley, 1966; Thomas, 1962; Ramsay \& Broadhurst, 1968; Weiss, 1964; Spatt \& Goldenberg, 1993; Brugger, Monsch, Salmon, \& Butters, 1996). Some previous work has shown that RNG performance correlates with the verbal fluency task for normal eight and twelve-year old children (Pureza, Jacobsen, Oliveira, \& Fonseca, 2011). For number preferences in children and adults, Towse, Loetscher, and Brugger (2014) showed that associations and dissociations appeared between adults' and children's number preferences. RNG performance has also been investigated in relation to head rotation in adults and children. While adults did demonstrate significantly different behavior regarding left and right head rotation under randomization 
performance, school-aged children did not. The authors attributed this effect to potential developmental alterations in number representations (Sosson, Georges, Guillaume, Schuller, \& Schiltz, 2018). Less information has been gathered about RNG and EF in school-aged children. In this paper we will address RNG in normally developing children and adolescents.

In attempt to explore different variables influencing EF in Brazilian children between six and 12 years old, Jacobsen, de Mello, Kochhann, and Fonseca (2017) showed that age was the most prominent predictor with regards to RNG performance, while parental education influenced only a small percentage of performance variance (Jacobsen, de Mello, Kochhann, \& Fonseca, 2017). Rabinowitz, Dunlap, Grant, and Campione (1989) were among the first to investigate age effects and RNG; 30 young children (mean age of 87 months), 30 children studying in the fifth grade (mean age of 136 months) and 30 first-year college students were tested. In their work first graders produced random sequences but used more counting strategies (series) than both the fifth graders and the college students. Also, Towse and Mclachlan (1999) recruited children aged from four to 11 and showed that children under the age of five manifest significant difficulties in this type of procedure and that their performance improved according to age, and speed requirements (Towse \& Mclachlan, 1999).

Regarding developmental disorders, studies support that children within the Autism Spectrum Disorder (ASD) are poor randomizers (Boucher, 1977; Brugger, 1997; Frith, 1972). Similarly, Rinehart, Bradshaw, Moss, Brereton, and Tonge (2006) in a 10 digit-randomization task (i.e., digits from 1 to 10) examined differences in the randomization performance in children with autism (mean age $=13.4$ years) and Asperger's syndrome (mean age $=10.6$ years) compared to age-control normal counterparts (mean age $=13.0$ years and 10.6 years respectively). More number repetitions were found for the children in the autism group and more stereotyped responses for the children belonging to the Asperger's syndrome group as compared to the control subjects. However, Gilbert, Bird, Brindley, Frith, \& Burgess (2008) on a button-press randomization task did not show behavioral differences between children within ASD and normally developing children.

Neuroimaging studies demonstrated that in the brain EF depend highly upon the pre-frontal lobes (Tsujimoto, 2008). Evidence indicates that the pre-frontal lobes mature last in comparison to other brain structures, during late childhood and early adolescence; that is the Pre-frontal Cortex (PFC) is subjected to neuronal and synaptic changes (Tsujimoto, 2008). It has been noted that not until a person is in their 30 years of age, do these brain loci mature completely (Johnson, Blum, \& Giedd, 2009; Sowell et al., 2003). In a similar vein, Gauvrit, Zenil, Soler-Toscano, Delahaye, and Brugger (2017) in a series of random generation experiments demonstrated that performance improves with age and reaches a plateau at 25 years before it starts declining.

Stroop task (Stroop, 1935) has traditionally been used as a measure of EF, especially for selective attention and inhibition (Kiyonaga \& Egner, 2014; Lamers, Roelofs, \& Rabeling-Keus, 2010). The Stroop task has also been shown to correlate with some aspects of RNG (Brugger, 1997; Brugger, Pietzsch, Weidmann, Biro, \& Alon, 1995). The Greek version of the Stroop task includes three parts lasting 45 seconds each (Zafiri \& Kosmidis, 2008). For each subset, the correct responses constitute the score. An interference score reflecting the "Stroop conflict" is calculated (Lovallo, Yechiam, Sorocco, Vincent, \& Collins, 2006; Perlstein, Carter, Barch, \& Baird, 1998). In this work, the Greek version of the Stroop Color Word Test (Zafiri \& Kosmidis, 2008) was administered to investigate children's and adolescents' performance and to see if it may or may not correlate with the randomness indices that indicate stereotypy (e.g., adjacent responses). These results will give insight into the children's and adolescents' ability of inhibition (Towse \& Neil, 1998; Miyake et al., 2000).

\subsection{Randomness Indices}

Several indices have been proposed as measures of randomness in RNG tasks. Seven indices that have previously been used in RNG tasks (Proios, Asaridou, \& Brugger, 2008), and are generated by the RgCalc program (Towse \& Neil, 1998), are Coupon, Mean Repetition Gap (Mean RG), Redundancy (R) Turning Point Index (TPI), Runs, Adjacency combined score (A comb), and Evan's Random Number Generation (RNG). According to Towse and Neil (1998) and their principal component analysis (PCA), these seven indices load on two different factors, termed "equality of response usage" and "prepotent associates", respectively. R, Coupon, and Mean RG comprise the former factor that shows whether someone employs responses equally, whereas A comb, TPI, RNG and Runs Score comprise the latter factor and demonstrates one's ability to avoid stereotypy (Towse, 1998; Towse \& Neil, 1998, p. 590). Miyake et al. (2000) also replicated the above factor structure, adding that the indices included in the "equality of response usage" component tap the EF of inhibition, and the indices that form the "prepotent associates" component are indicative of the ability to update and monitor working memory information (Miyake et al., 2000; Miyake, Witzki, \& Emerson, 2001).

Coupon score refers to the mean production of digits before the production of all the digits alternatives (Towse \& 
Neil, 1998). For instance, in the RNG task if a participant utters the sequence " $2,4,1,3,6,5$ " the Coupon score would be the lowest, thus the optimal. The longer the sequence before all alternatives are produced the higher the Coupon score, and therefore, the worse the randomization performance (Audiffren, Tomporowski, \& Zagrodnik, 2009). On the other hand, the Mean Repetition Gap score (Mean RG) is the mean gap or distance between the appearance of the same number. To cite an example, in the sequence " $3,5,2,1,3,4,6$ " there is a gap of four for the number " 3 ". Hence, when someone repeats a number frequently the Mean RG will be lower (Audiffren et al., 2009). Redundancy $(\mathrm{R})$ is a percentage score denoting the deviation from randomness, the more random the less redundant a sequence. Thus, R scores of $10 \%$ or $20 \%$ signify a more random sequence than an R score of $70 \%$ (For a mathematical approach of R score you can see Towse \& Neil, 1998). Turning Point Index (TPI) measures the change between ascending and descending series (Geisseler et al., 2016). For example, in the sequence " $2,3,5,1,4,2$ " there are two turning points: one at the digit " 5 " and one at the digit " 4 ". The turning points are compared to theoretical values of turning points of random sequences (Audiffren et al., 2009). A TPI score of 100 is the optimal score concerning randomization, whereas a TPI lower than 100 reflects a counting tendency (i.e., not as many alterations of ascending and descending sequences as expected). Finally, a TPI score higher than 100 shows a strategy of changing ascending and descending sequence more often than expected (Audiffren et al., 2009). The Runs score (Runs) is a great measure of counting strategies. The higher the Runs the longer the ascending and descending sequences. Consequently, a lower Runs score shows better randomization performance (Towse \& Neil, 1998). The Adjacency combined score (A comb) is a percentage of successive ascending or descending answers (e.g., "4,5" or "3,2"; Audiffren et al., 2009). High A comb scores indicate a stereotypy in responses (Towse \& Neil, 1998). On the other hand, Evan's Random Number Generation or Random Number Generation (RNG) refers to the frequency of pairs. Evan's RNG ranges from 0 to 1 with higher RNG index signifying more deviation from theoretical distributions, and therefore poorer randomization performance (Evans, 1978; Towse, \& Neil, 1998).

\subsection{Hypotheses}

We hypothesize that the EF underlying performance on an RNG task will be improved in adolescents compared to the youngest counterparts. We also expect that performance on the Stroop Test (Stroop, 1935) will correlate with the subjects' performance on the RNG task indices that load in the "prepotent associates" component and tap inhibition (Towse \& Neil, 1998; Miyake et al., 2000).

\section{Method}

\subsection{Participants}

A group of 106 children and adolescents aged from 7 to 15 (54 female) with a mean age of 132 months ( $\mathrm{SD}=27.1$ months) were divided into three groups according to their age: $7-9(\mathrm{n}=41$, mean age $=105.5$ months, $\mathrm{SD}=8.54$ months, age range: $89-119$ months), $10-12$ ( $\mathrm{n}=40$, mean age $=135.4$ months, $\mathrm{SD}=9.29$ months, age range: $120-154$ months), 13-15 ( $\mathrm{n}=25$, mean age=172 months, $\mathrm{SD}=9.12$ months, age range: $156-185$ months). None of the participants had a history of learning disabilities or developmental disorder (based on the school records and student reports). Children and adolescents were recruited as part of regular curriculum (2019) in three elementary schools and four high-schools in the cities of Thessaloniki, Ioannina and Kalamata in northern, western, and southern Greece, respectively and participated face-to face in this study.

\subsection{Procedures}

Participants' next of kin were informed about the study by the school committees. A letter informing about the purpose of the study, the procedure, and a consent form were sent via mail. Children and adolescents were tested in the school premises individually, while anonymity and confidentiality were kept throughout the process. All participants were informed that they were free to withdraw from testing at any time. Their wellbeing and confidentiality were protected by the researchers and testing took place according to the ethical guideline of the 1964 Declaration of Helsinki (Rickham, 1964).

\subsection{Measures}

The Mental Dice Task (MDT; Brugger, Landis, \& Regard, 1990; Brugger, Milicevic, Regard, \& Cook, 1993; Brugger et al., 1996) asks subjects to imagine repetitively throwing a die and report the number that is rolled. In this study students were required to utter a random sequence of digits from 1 to 6 (i.e., imitating a die). All participants had a practice run of 10 responses and then were asked to produce 66 responses in time with a metronome that was set at $1 \mathrm{beat} / \mathrm{sec}$. After verbal responses were recorded, the data was uploaded to RgCalc program (Towse \& Neil, 1998) in order to examine the performance of randomness. For every student a pseudorandom sequence was produced by RgCalc for comparison with all subjects.

Seven indices of randomness were used: Coupon, Mean Repetition Gap (Mean RG), Redundancy (R), Turning 
Point Index (TPI), Runs, Adjacency combined score (A comb), and Evan's Random Number Generation (RNG) (For further explanation please see Towse \& Neil, 1998).

\subsection{Data Analyses}

For the statistical analysis the Statistical Package for the Social Sciences (SPSS 22.0) was used. For the effect of age on randomness parametric and non-parametric tests were applied: F-test (ANOVA), Welsch, and Kruskal-Wallis. Welsch test was applied when homogeneity of distributions did not exist, while Kruskal-Wallis test was preferred when histogram was not symmetrical and the population was small $(\mathrm{n}<30)$. Post-hoc analyses included the Bonferroni correction for the F-test, the Tamhane correction for the Welsch test, and the Mann-Whitney test for the Kruskal-Wallis test. The level of significance was set at .05 ( $\alpha=.05)$

\section{Results}

\subsection{Factorial Structure of the RNG Indices}

The seven randomization indices derived from the data of our sample were calculated by the RgCalc program. These seven indices were subjected to Principal Component Analysis (Determinant of correlation matrix $>.0001$, $\mathrm{KMO}=.613>.6$, Bartlett's Test of Sphericity $\mathrm{p}<.05$ ) with an orthogonal (varimax) rotation. From examination of the scree plot (Figure 1), two factors with eigenvalues larger than 1 were extracted, together accounting for $70.86 \%$ of the variance. The indices that comprise the two factors and their loadings are shown in Table 1.

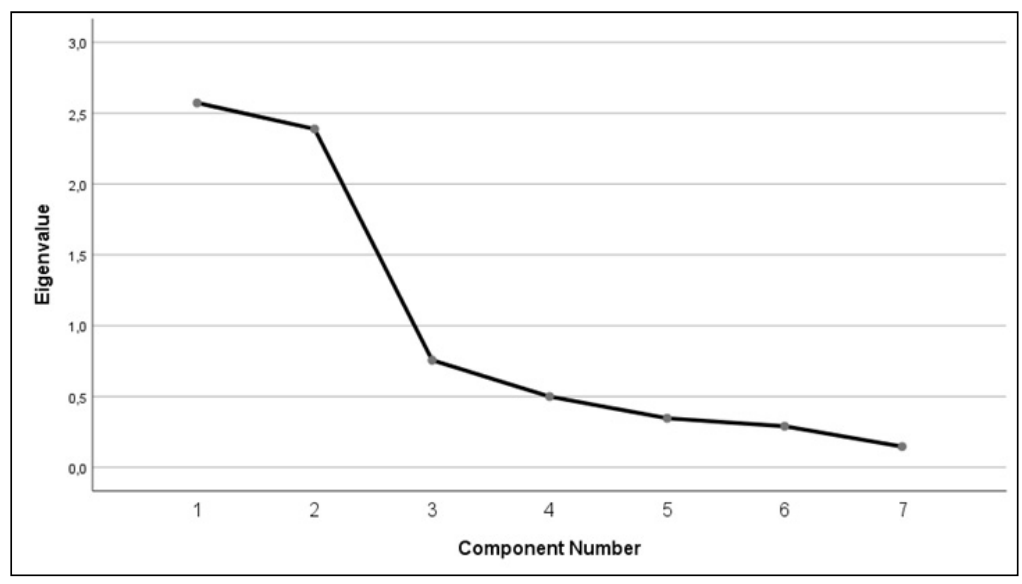

Figure 1. Scree-plot of 2 components with eigenvalues greater than 1

Table 1. RNG indices ordered by loading size in the two factors

\begin{tabular}{lcc}
\hline RNG Indices & Factor 1 & Factor 2 \\
\hline Adjacency & .919 & \\
Turning Point Index & -.825 & \\
Runs Score & .783 & \\
RNG & .634 & .884 \\
Redundancy & & -.881 \\
Repetition Gap (mean) & & .866 \\
Coupon & & \\
\hline
\end{tabular}

\subsection{Age Effect}

Table 2 illustrates the age effect on indices of randomness. In particular, the Kruskal-Wallis test indicates statistically significant differences on $\mathrm{R}$ among the three groups $(\mathrm{KW}=6.71, \mathrm{p}=.03)$. Pairwise comparisons with the Mann-Whitney test showed that $\mathrm{R}$ is greater in the first group (7-9 years of age) compared to the second group (10-12 years of age). In contrast, the F-test (ANOVA) was performed on Evan's Random Number Generation 
(RNG). The age had a significant effect on this index $(\mathrm{F}=5.36, \mathrm{p}=.006)$. Pairwise comparison with the Bonferroni correction showed that RNG is higher in Group 1 (7-9 years of age) in comparison to Group 3 (13-15 years of age). Furthermore, the youngest participants (Group 1) had a higher A comb score than their older counterparts (Group 1> Group 3; KW=10.92, p=.004). Finally, the youngest children (Group 1) had a smaller Mean RG than the adolescents (Group 3; KW=6.92, $\mathrm{p}=.03$ ).

On the other hand, the F-test did not reveal any significant differences among the three groups on TPI $(\mathrm{F}=1.70$, $\mathrm{p}=.18)$ and Runs $(\mathrm{F}=2.80, \mathrm{p}=.06)$. Lastly, according to the Kruskal-Wallis test there were no significant differences on Coupon among the three age groups $(\mathrm{KW}=4.10, \mathrm{p}=.12)$.

Table 2. Age effect on indices of RNG

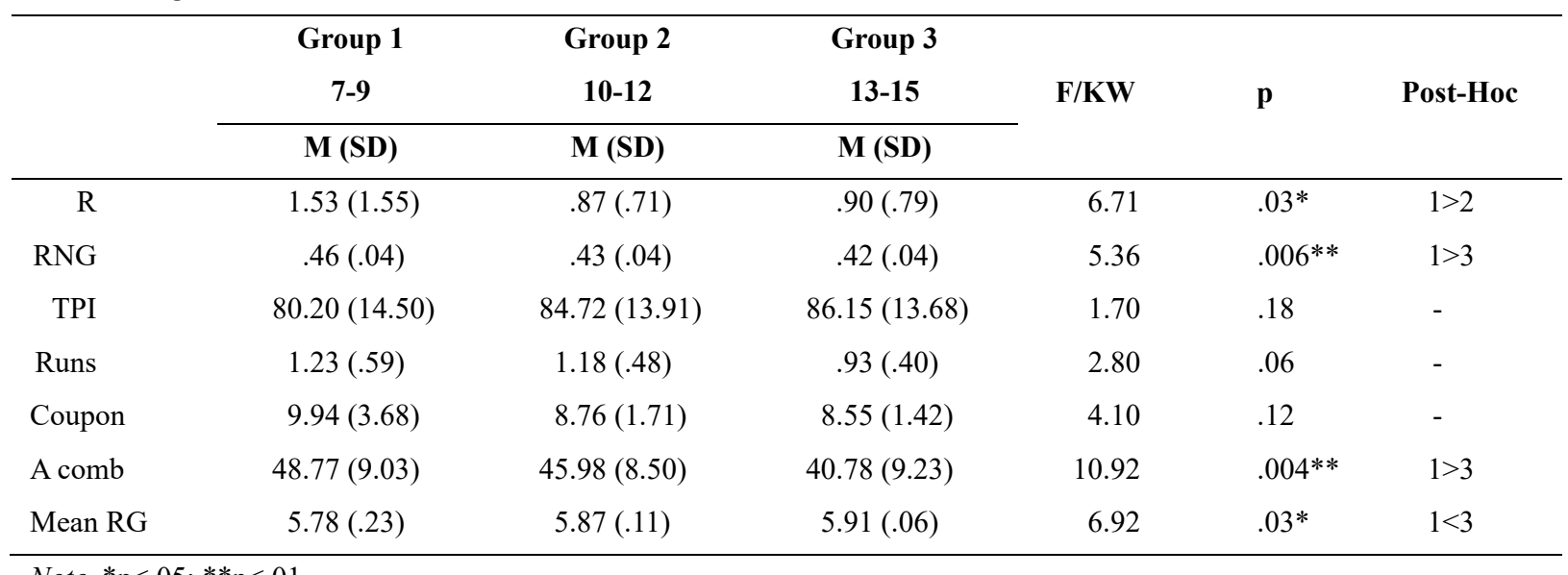

Note. ${ }^{*} \mathrm{p}<.05 ; * * \mathrm{p}<.01$.

Note. $\mathrm{M}=$ mean, $\mathrm{SD}=$ Standard Deviation, $\mathrm{R}=$ Redundancy, $\mathrm{RNG}=$ Evan's Random Number Generation, $\mathrm{TPI}=\mathrm{Turning}$ Point Index, $\mathrm{A}$ comb= Adjacency combined, Mean $\mathrm{RG}=$ Repetition Gap (mean). F= F-test, KW= Kruskal - Wallis test.

\subsection{Gender effect}

Table 3 indicates the gender effect on the different indices of randomness. Independent sample t-test and Mann-Whitney $U$ test revealed that none of these indices was statistically significantly different between the two groups.

Table 3. Gender effect on RNG indices

\begin{tabular}{|c|c|c|c|c|c|c|}
\hline & \multicolumn{2}{|c|}{ Male } & \multicolumn{2}{|c|}{ Female } & \multirow{2}{*}{$\mathbf{t}$} & \multirow{2}{*}{$\mathbf{p}$} \\
\hline & $\mathbf{M}$ & SD & $\mathbf{M}$ & SD & & \\
\hline $\mathrm{R}$ & 1.11 & 1.13 & 1.15 & 1.20 & -.154 & .878 \\
\hline RNG & .43 & .05 & .45 & .03 & -1.79 & .075 \\
\hline TPI & 84.32 & 14.48 & 82.33 & 13.95 & .72 & .470 \\
\hline Runs & 1.06 & .48 & 1.22 & .55 & -1.53 & .120 \\
\hline Coupon & 9.36 & 1.93 & 8.98 & 3.22 & .74 & .450 \\
\hline A comb & 44.08 & 9.65 & 47.53 & 8.74 & -1.92 & .057 \\
\hline Mean RG & 5.86 & .13 & 5.82 & .20 & 1.17 & .240 \\
\hline
\end{tabular}

Note. ${ }^{*} \mathrm{p}<.05 ; * * \mathrm{p}<.01$.

Note. $\mathrm{M}=$ mean, $\mathrm{SD}=$ Standard Deviation, $\mathrm{R}=$ Redundancy, $\mathrm{RNG}=$ Evan's Random Number Generation, TPI= Turning Point Index, $\mathrm{A}$ comb= Adjacency combined, Mean $\mathrm{RG}=$ Repetition Gap (mean). 


\subsection{Comparison of Randomness between Participants and Simulated Data (RgCalc)}

Comparisons between the participants' (i.e., children and adolescents) responses and the 106 pseudorandom sequences produced by the RgCalc program are presented in Table 4. T-test indicated significant differences between groups for all indices of randomness (Table 4). We found R, TPI, and Coupon to be significantly lower for the participant group (i.e., children and adolescents) compared to the RgCalc sequences. On the other hand, RNG, Runs, A comb, and Mean RG were significantly higher for the participant group.

Table 4. Comparison of data between participants and simulated data on indices of randomness

\begin{tabular}{|c|c|c|c|c|c|c|}
\hline & \multicolumn{2}{|c|}{ Participants } & \multicolumn{2}{|c|}{ RgCalc Sequencies } & \multirow{2}{*}{$\mathbf{t}$} & \multirow{2}{*}{$\mathbf{p}$} \\
\hline & $\mathbf{M}$ & SD & $\mathbf{M}$ & SD & & \\
\hline $\mathrm{R}$ & 1.13 & 1.16 & 2.01 & 1.36 & -5.04 & $<.001 *$ \\
\hline RNG & .44 & .04 & .37 & .03 & 11.96 & $<.001^{*}$ \\
\hline TPI & 83.31 & 14.18 & 92.46 & 8.34 & -5.72 & $<.001 *$ \\
\hline Runs & 1.14 & .52 & .47 & .29 & 11.59 & $<.001^{*}$ \\
\hline Coupon & 9.17 & 2.66 & 14.56 & 3.15 & -13.43 & $<.001^{*}$ \\
\hline A comb & 45.83 & 9.32 & 28.21 & 5.83 & 16.49 & $<.001 *$ \\
\hline Mean RG & 5.84 & .17 & 5.51 & .19 & 13.31 & $<.001^{*}$ \\
\hline
\end{tabular}

Note. ${ }^{*} \mathrm{p}<.05 ; * * \mathrm{p}<.01$.

Note. $\mathrm{M}=$ mean, $\mathrm{SD}=$ Standard Deviation, $\mathrm{R}=$ Redundancy, $\mathrm{RNG}=$ Evan's Random Number Generation, TPI= Turning Point Index, $\mathrm{A}$ comb= Adjacency combined, Mean RG= Repetition Gap (mean).

\subsection{Correlations of the RNG Indices and the Stroop Test}

Table 5 shows the correlations (Pearson $r$ ) of the Stroop performance and the indices of randomness. As it can be seen none of these indices correlated significantly with performance on the Stroop Test (raw Interference Score).

Table 5. Correlation between Stroop task performance and indices of random number generation

\begin{tabular}{cllllllll}
\hline & & R & RNG & TPI & Runs & Coupon & A comb & Mean RG \\
\hline \multirow{2}{*}{ Stroop performance } & $\mathrm{r}$ & -.133 & .015 & .145 & -.054 & -.075 & -.116 & .055 \\
& $\mathrm{p}$ & .174 & .875 & .139 & .580 & .444 & .236 & .573 \\
& $\mathrm{~N}$ & 106 & 106 & 106 & 106 & 106 & 106 & 106 \\
\hline
\end{tabular}

Note. ${ }^{*} \mathrm{p}<.05 ; * * \mathrm{p}<.01$.

Note. $\mathrm{R}=$ Redundancy, $\mathrm{RNG}=$ Evan's Random Number Generation, TPI= Turning Point Index, A comb= Adjacency combined, Mean $\mathrm{RG}=$ Repetition Gap (mean).

\section{Discussion}

All indices of the randomization performance showed improvements according to age, yet only four out of seven indices demonstrated significant differences: R, Mean RG, A comb, and RNG. R score was significantly lower for the age group of 10 to 12 years old compared to the youngest group, whereas Mean RG, A comb and RNG were significantly better in the oldest group in comparison to the youngest group. This suggests that children and adolescents may have distinctive differences regarding development of RNG indices and EF. Huizinga, Dolan and Van der Molen (2006) showed that EF mature differentially and demonstrate dissimilar developmental trajectories. This is like our work which also shows the developmental changes of the randomization performance.

Since RNG and A comb indices reflect one's ability to inhibit overlearned and stereotypical responses (Miyake et al., 2000), both the measures found in our work were significantly improved in the adolescents (i.e., oldest group) compared to the youngest group. Adolescents' randomization performance was improved compared to the second age group, also, but not significantly. Similar findings are provided by Brocki and Bohlin (2004), who reported a 
developmental change of inhibition.

The PCA performed in the present study revealed consistent findings with Towse and Neil's (1998) about the indices of randomness. While Towse and Neil (1998) performed a PCA in adult responses of a 10-digit randomization task, we did with responses of school-aged children and adolescents on the MDT. This is interesting and extends the literature of the randomization tasks.

No gender effect was found on the randomization performance in any of the age groups and our finding is in line with some previous research regarding the effect of gender on EF (Brocki \& Bohlin, 2004; Jacobsen et al., 2017). This is contrary to other studies that have reported gender effects on EF (Dias, Menezes, \& Seabra, 2013; Wiebe, Espy, \& Charak, 2008).

Children's and adolescents' responses were significantly different from pseudorandom sequences produced by the RgCalc program, exhibiting two major characteristics: firstly, a tendency to generate numbers in their natural order (e.g., counting) as indicated by the higher RNG, Runs, and A comb scores and the lower TPI score. Secondly, the students generated number sequences in which all alternatives are used equally and are evenly distributed as indicated by the higher Mean RG score and the lower R and Coupon scores. Children and adolescents might not be fully able to inhibit prepotent or stereotyped responses while at the same time, they might perceive randomness as an even appearance of all response alternatives. Human perception and generation of randomness is characterized by such biases (Audiffren et al., 2009; Jahanshahi et al., 1998; Spatt \& Goldenberg, 1993).

The Stroop test results did not correlate with the inhibition indices of randomization performance (i.e., A comb, TPI, Runs, RNG). In contrast, Brugger et al. (1995) found a moderate positive correlation between the Stroop task and the MDT ( $r=.30, p=.007)$ in healthy adults. Also, Friedman and Miyake (2004) found that Stroop performance and the indices that indicate stereotypy (i.e., "prepotent associates") correlate significantly in young adults. Whereas like our findings, Maes, Eling, Reelick, \& Kessels (2011) indicated that the Stroop task performance did not correlate significantly with an RNG task in patients with cognitive decline. On this matter one may wonder whether there is a developmental effect. One idea is that RNG and Stroop tasks examine diverse aspects of inhibition engaging adjacent but not identical neural pathways.

\subsection{Study Limitations}

The limitations of the present work include the following: the fact that the Greek version of the Stroop task is standardized to the adult population, and the relatively small sample size of this study. Normative data do not exist for the Greek children at the population level. The limits of what is possible in RNG tasks and EF in the Greek language for this age group have not yet been explored. Inclusion of different versions of the Stroop task and of more neuropsychological assessment tools could be used to examine interactions of RNG tasks with EF. The development of the randomization performance was based on specific age ranges using comparative analyses. Using a larger sample, then age can be analysed as a continuous variable. This study could be extended to include populations from special educational settings for the evaluation of EF in atypically developing children and adolescents.

\subsection{Conclusion}

As our findings were in agreement with previous work (Rabinowitz et al., 1989) future studies can continue to investigate age-related differences and include larger as well as different groups: pre-school children and school-aged children and adolescents. Notwithstanding the shortcomings, the findings of our work conclude that there is an age effect on randomization performance with adolescents demonstrating improved performance as compared to younger children. We did not find a significant gender effect and this is in accordance with some latest findings as Guerra et al. (2021) reported a gender effect only on some EF tasks while Slot and von Suchodoletz, (2018) found insignificant results on gender differences in pre-school children. Although, a recent meta-analysis found that gender plays a significant role on EF in children (Cortés Pascual et al., 2019). Undoubtedly, more research is needed to cast light on this phenomenon. These conclusions suggest that in a Greek sample gender effects do not exist with regard to EF and more data from different cultures can advance our knowledge.

\subsection{Recommendations for Future Research}

Future research can further explore more dimensions of random number generation performance in school-aged children and adolescents. Other populations that demonstrate EF deficits can be investigated such as children with Attention Deficit Hyperactivity Disorder (ADHD) or children within the ASD (Leno et al., 2018; Pineda-Alhucema, Aristizabal, Escudero-Cabarcas, Acosta-Lopez, \& Vélez, 2018). Finally, the inclusion of more neuropsychological tools and cognitive measurements along with academic achievement could enhance our understanding on this topic. 


\section{Acknowledgments}

The authors wish to thank Dr. Salomi Asaridou for her help and suggestions on treating and analyzing the data from RgCalc program. We thank the heads and teachers at the school units for helping us recruit participants and all schools/students.

\section{References}

Alloway, T. P., \& Alloway, R. G. (2010). Investigating the predictive roles of working memory and IQ in academic $\begin{array}{lllll}\text { attainment. Journal of experimental child psychology, 106(1), 20-29. } & \text {. }\end{array}$ https://doi.org/10.1016/j.jecp.2009.11.003

Alloway, T. P., Gathercole, S. E., Kirkwood, H., \& Elliott, J. (2009). The cognitive and behavioral characteristics of children with low working memory. Child development, 80(2), 606-621. https://doi.org/10.1111/j.1467-8624.2009.01282.x

Audiffren, M., Tomporowski, P. D., \& Zagrodnik, J. (2009). Acute aerobic exercise and information processing: modulation of executive control in a Random Number Generation task. Acta psychologica, 132(1), 85-95. https://doi.org/10.1016/j.actpsy.2009.06.008

Boucher, J. (1977). Alternation and sequencing behaviour, and response to novelty in autistic children. Journal of Child Psychology and Psychiatry, 18(1), 67-72. https://doi.org/10.1111/j.1469-7610.1977.tb00417.x

Baddeley, A. D. (1966). The capacity for generating information by randomization. The Quarterly journal of experimental psychology, 18(2), 119-129. https://doi.org/10.1080/14640746608400019

Brocki, K. C., \& Bohlin, G. (2004). Executive functions in children aged 6 to 13: A dimensional and developmental study. Developmental neuropsychology, 26(2), 571-593. https://doi.org/10.1207/s15326942dn2602_3

Brugger, P. (1997). Variables that influence the generation of random sequences: An update. Perceptual and motor skills, 84(2), 627-661.

Brugger, P., Landis, T., \& Regard, M. (1990). A 'sheep-goat effect'in repetition avoidance: Extra-sensory perception as an effect of subjective probability?. British Journal of Psychology, 81(4), 455-468. https://doi.org/10.1111/j.2044-8295.1990.tb02372.x

Brugger, P., Milicevic, A., Regard, M., \& Cook, N. D. (1993). Random-number generation and the menstrual cycle: preliminary evidence for a premenstrual alteration of frontal lobe functioning. Perceptual and motor skills, 77(3), 915-921.

Brugger, P., Monsch, A. U., Salmon, D. P., \& Butters, N. (1996). Random number generation in dementia of the Alzheimer type: A test of frontal executive functions. Neuropsychologia, 34(2), 97-103. https://doi.org/10.1016/0028-3932(95)00066-6

Brugger, P., Pietzsch, S., Weidmann, G., Biro, P., \& Alon, E. (1995). Stroop-type interference in random-number generation. Psychological Reports, 77(2), 387-390. https://doi.org/10.2466/pr0.1995.77.2.387

Chan, R. C., Shum, D., Toulopoulou, T., \& Chen, E. Y. (2008). Assessment of executive functions: Review of instruments and identification of critical issues. Archives of clinical neuropsychology, 23(2), 201-216. https://doi.org/10.1016/j.acn.2007.08.010

Cortés Pascual, A., Moyano Muñoz, N., \& Quilez Robres, A. (2019). The relationship between executive functions and academic performance in primary education: review and meta-analysis. Frontiers in psychology, 10, 1582. https://doi.org/10.3389/fpsyg.2019.01582

Diamond, A. (2006). The early development of executive functions. Lifespan cognition: Mechanisms of change, 210, 70-95. https://doi.org/10.1093/acprof:oso/9780195169539.003.0006

Dias, N. M., Menezes, A., \& Seabra, A. G. (2013). Age differences in executive functions within a sample of Brazilian children and adolescents. The Spanish Journal of Psychology, 16. https://doi.org/10.1017/sjp.2013.12

Evans, F. J. (1978). Monitoring attention deployment by random number generation: An index to measure subjective randomness. Bulletin of the Psychonomic Society, 12(1), 35-38. https://doi.org/10.3758/BF03329617

Faria, C. D. A., Alves, H. V. D., \& Charchat-Fichman, H. (2015). The most frequently used tests for assessing executive functions in aging. Dementia \& Neuropsychologia, 9(2), 149-155. 
https://dx.doi.org/10.1590/1980-57642015DN92000009

Friedman, N. P., \& Miyake, A. (2004). The relations among inhibition and interference control functions: a latent-variable analysis. Journal of experimental psychology: General, 133(1), 101. https://doi.org/10.1037/0096-3445.133.1.101

Frith, U. (1972). Cognitive mechanisms in autism: Experiments with color and tone sequence production. Journal of Autism and Childhood Schizophrenia, 2(2), 160-173. https://doi.org/10.1007/BF01537569

Gauvrit, N., Zenil, H., Soler-Toscano, F., Delahaye, J. P., \& Brugger, P. (2017). Human behavioral complexity peaks at age 25. PLoS computational biology, 13(4), e1005408. https://doi.org/10.1371/journal.pcbi.1005408

Geisseler, O., Pflugshaupt, T., Buchmann, A., Bezzola, L., Reuter, K., Schuknecht, B., ... \& Brugger, P. (2016). Random number generation deficits in patients with multiple sclerosis: characteristics and neural correlates. Cortex, 82, 237-243. https://doi.org/10.1016/j.cortex.2016.05.007

Gilbert, S. J., Bird, G., Brindley, R., Frith, C. D., \& Burgess, P. W. (2008). Atypical recruitment of medial prefrontal cortex in autism spectrum disorders: An fMRI study of two executive function tasks. Neuropsychologia, 46(9), 2281-2291. https://doi.org/10.1016/j.neuropsychologia.2008.03.025

Guerra, A., Hazin, I., Guerra, Y., Roulin, J. L., Le Gall, D., \& Roy, A. (2021). Developmental profile of executive functioning in school-age children from Northeast Brazil. Frontiers in Psychology, 11, 3796. https://doi.org/10.3389/fpsyg.2020.596075

Huizinga, M., Dolan, C. V., \& Van der Molen, M. W. (2006). Age-related change in executive function: Developmental trends and a latent variable analysis. Neuropsychologia, 44(11), 2017-2036. https://doi.org/10.1016/j.neuropsychologia.2006.01.010

Jacobsen, G. M., de Mello, C. M., Kochhann, R., \& Fonseca, R. P. (2017). Executive functions in school-age children: Influence of age, gender, school type and parental education. Applied Cognitive Psychology, 31(4), 404-413. https://doi.org/10.1002/acp.3338

Jahanshahi, M., Profice, P., Brown, R. G., Ridding, M. C., Dirnberger, G., \& Rothwell, J. C. (1998). The effects of transcranial magnetic stimulation over the dorsolateral prefrontal cortex on suppression of habitual counting during random number generation. Brain: a journal of neurology, 121(8), 1533-1544. https://doi.org/10.1093/brain/121.8.1533

Johnson, S. B., Blum, R. W., \& Giedd, J. N. (2009). Adolescent maturity and the brain: the promise and pitfalls of neuroscience research in adolescent health policy. Journal of Adolescent Health, 45(3), 216-221. https://doi.org/10.1016/j.jadohealth.2009.05.016

Kiyonaga, A., \& Egner, T. (2014). The working memory Stroop effect: When internal representations clash with external stimuli. Psychological science, 25(8), 1619-1629. https://doi.org/10.1177/0956797614536739

Lamers, M. J., Roelofs, A., \& Rabeling-Keus, I. M. (2010). Selective attention and response set in the Stroop task. Memory \& Cognition, 38(7), 893-904. https://doi.org/10.3758/MC.38.7.893

Leno, V. C., Chandler, S., White, P., Pickles, A., Baird, G., Hobson, C., ... \& Simonoff, E. (2018). Testing the specificity of executive functioning impairments in adolescents with ADHD, ODD/CD and ASD. European child \& adolescent psychiatry, 27(7), 899-908. https://doi.org/10.1007/s00787-017-1089-5

Lovallo, W. R., Yechiam, E., Sorocco, K. H., Vincent, A. S., \& Collins, F. L. (2006). Working memory and decision-making biases in young adults with a family history of alcoholism: Studies from the Oklahoma Family Health Patterns Project. Alcoholism: Clinical and Experimental Research, 30(5), 763-773. https://doi.org/10.1111/j.1530-0277.2006.00089.x

Maes, J. H., Eling, P. A., Reelick, M. F., \& Kessels, R. P. (2011). Assessing executive functioning: On the validity, reliability, and sensitivity of a click/point random number generation task in healthy adults and patients with cognitive decline. Journal of clinical and experimental neuropsychology, 33(3), 366-378. https://doi.org/10.1080/13803395.2010.524149Meixner, J. M., Warner, G. J., Lensing, N., Schiefele, U., \& Elsner, B. (2019). The relation between executive functions and reading comprehension in primary-school students: A cross-lagged-panel analysis. Early Childhood Research Quarterly, 46, 62-74. https://doi.org/10.1016/j.ecresq.2018.04.010

Miyake, A., Friedman, N. P., Emerson, M. J., Witzki, A. H., Howerter, A., \& Wager, T. D. (2000). The unity and diversity of executive functions and their contributions to complex "frontal lobe" tasks: A latent variable analysis.Cognitive psychology, 41(1), 49-100. https://doi.org/10.1006/cogp.1999.0734 
Miyake, A., Witzki, A. H., \& Emerson, M. J. (2001). Field dependence-independence from a working memory perspective: A dual-task investigation of the Hidden Figures Test. Memory, 9(4-6), 445-457. https://doi.org/10.1080/09658210143000029

Nyongesa, M. K., Ssewanyana, D., Mutua, A. M., Chongwo, E., Scerif, G., Newton, C. R., \& Abubakar, A. (2019). Assessing executive function in adolescence: A scoping review of existing measures and their psychometric robustness. Frontiers in psychology, 10, 311. https://doi.org/10.3389/fpsyg.2019.00311

Perlstein, W. M., Carter, C. S., Barch, D. M., \& Baird, J. W. (1998). The Stroop task and attention deficits in schizophrenia: a critical evaluation of card and single-trial Stroop methodologies. Neuropsychology, 12(3), 414. https://doi.org/10.1037/0894-4105.12.3.414

Pineda-Alhucema, W., Aristizabal, E., Escudero-Cabarcas, J., Acosta-Lopez, J. E., \& Vélez, J. I. (2018). Executive function and theory of mind in children with ADHD: A systematic review. Neuropsychology Review, 28(3), 341-358. https://doi.org/10.1007/s11065-018-9381-9

Proios, H., Asaridou, S. S., \& Brugger, P. (2008). Random number generation in patients with aphasia: A test of executive functions. Acta Neuropsychologica, 6(2), 157-168.

Rabinowitz, F. M., Dunlap, W. P., Grant, M. J., \& Campione, J. C. (1989). The rules used by children and adults in attempting to generate random numbers. Journal of Mathematical Psychology, 33(3), 227-287. https://doi.org/10.1016/0022-2496(89)90009-6

Ramsay, R. W., \& Broadhurst, A. (1968). The non-randomness of attempts at random responses: relationships with personality variables and psychiatric disorder. British Journal of Psychology, 59(3), 299-304. https://doi.org/10.1111/j.2044-8295.1968.tb01144.x

Rickham, P. P. (1964). Human experimentation. Code of ethics of the world medical association. Declaration of Helsinki. British medical journal, 2(5402), 177-177.

Rinehart, N. J., Bradshaw, J. L., Moss, S. A., Brereton, A. V., \& Tonge, B. J. (2006). Pseudo-random number generation in children with high-functioning autism and Asperger's disorder: Further evidence for a dissociation in executive functioning?. Autism, 10(1), 70-85. https://doi.org/10.1177/1362361306062011

Pureza, J. R., Jacobsen, G. M., Oliveira, R. G., \& Fonseca, R. P. (2011). Relationships between executive functions tasks in late childhood. Psychology \& Neuroscience, 4(3), 369-376. http://dx.doi.org/10.3922/j.psns.2011.3.010

Slot, P. L., \& von Suchodoletz, A. (2018). Bidirectionality in preschool children's executive functions and language skills: Is one developing skill the better predictor of the other?. Early Childhood Research Quarterly, 42, 205-214. https://doi.org/10.1016/j.ecresq.2017.10.005

Sosson, C., Georges, C., Guillaume, M., Schuller, A. M., \& Schiltz, C. (2018). Developmental changes in the effect of active left and right head rotation on random number generation. Frontiers in psychology, 9, 236. https://doi.org/10.3389/fpsyg.2018.00236

Sowell, E. R., Peterson, B. S., Thompson, P. M., Welcome, S. E., Henkenius, A. L., \& Toga, A. W. (2003). Mapping cortical change across the human life span. Nature neuroscience, 6(3), 309-315. https://doi.org/10.1038/nn1008

Stroop, J. R. (1935). Studies of interference in serial verbal reactions. Journal of experimental psychology, 18(6), 643.

Spatt, J., \& Goldenberg, G. (1993). Components of random generation by normal subjects and patients with dysexecutive syndrome. Brain and Cognition, 23(2), 231-242. https://doi.org/10.1006/brcg.1993.1057

Thomas, H. B. G. (1962). The "Supervisor"-A hypothetical mental function impaired by brain damage. Journal of Mental Science, 108(454), 329-346. https://doi.org/10.1192/bjp.108.454.329

Towse, J. N. (1998). On random generation and the central executive of working memory. British journal of psychology, 89(1), 77-101. https://doi.org/10.1111/j.2044-8295.1998.tb02674.x

Towse, J. N., Loetscher, T., \& Brugger, P. (2014). Not all numbers are equal: preferences and biases among children and adults when generating random sequences. Frontiers in psychology, 5, 19. https://doi.org/10.3389/fpsyg.2014.00019

Towse, J. N., \& Mclachlan, A. (1999). An exploration of random generation among children. British Journal of Developmental Psychology, 17(3), 363-380. https://doi.org/10.1348/026151099165348 
Towse, J. N., \& Neil, D. (1998). Analyzing human random generation behavior: A review of methods used and a computer program for describing performance. Behavior Research Methods, Instruments, \& Computers, 30(4), 583-591. https://doi.org/10.3758/BF03209475

Tsujimoto, S. (2008). The prefrontal cortex: Functional neural development during early childhood. The Neuroscientist, 14(4), 345-358. https://doi.org/10.1177/1073858408316002

Visu-Petra, L., Cheie, L., Benga, O., \& Miclea, M. (2011). Cognitive control goes to school: The impact of executive functions on academic performance. Procedia-Social and Behavioral Sciences, 11, 240-244. https://doi.org/10.1016/j.sbspro.2011.01.069

Wagenaar, W. A. (1972). Generation of random sequences by human subjects: A critical survey of literature. Psychological Bulletin, 77(1), 65. https://doi.org/10.1037/h0032060

Weiss, R. L. (1964). On producing random responses. Psychological Reports, 14(3), 931-941. https://doi.org/10.2466/pr0.1964.14.3.931

Wiebe, S. A., Espy, K. A., \& Charak, D. (2008). Using confirmatory factor analysis to understand executive control in preschool children: I. Latent structure. Developmental psychology, 44(2), 575. https://doi.org/10.1037/0012-1649.44.2.575

Zafiri, M., \& Kosmidis, M. H. (2008). Effects of demographic characteristics on the "Stroop conflict". Psychology: The Journal of the Hellenic Psychological Society, 15(4), 319. https://doi.org/10.12681/psy_hps.23847

\section{Copyrights}

Copyright for this article is retained by the author(s), with first publication rights granted to the journal.

This is an open-access article distributed under the terms and conditions of the Creative Commons Attribution license (http://creativecommons.org/licenses/by/4.0/). 